\title{
Pharmacological Treatment of Bipolar Disorder among Children and Adolescents
}

\author{
Joseph C. Blader, Ph.D. [Assistant Professor] and \\ Psychiatry Stony Brook State University of New York T: (631) 632-8675 F: (631) 632-8953 \\ Joseph.Blader@StonyBrook.edu
}

Vivian Kafantaris, M.D. [Associate Professor]

Psychiatry and Behavioral Sciences Albert Einstein College of Medicine T: (718) 470-8556 F: (718)

343-1659 VKafanta@lij.edu

\section{Summary}

There is growing recognition that bipolar disorder (BD) frequently first presents in adolescence.

Preadolescents with volatile behavior and severe mood swings also comprise a large group of patients whose difficulties may lie within the bipolar spectrum. However, the preponderance of scientific effort and clinical trials for this condition have focused on adults. This review summarizes the BD's complexity and diagnosis among young people. It proceeds to review the principles of pharmacotherapy, to assess current treatment options, and to highlight areas where evidence-based guidance is lacking. Recent developments have enlarged the range of potential treatments for BD. Nonetheless, differences in the phenomenology, course, and sequelae of BD among young people compel greater attention to the benefits and liabilities of therapy for those affected by this illness' early onset.

\section{PHENOMENOLOGY AND DIAGNOSTIC CONSIDERATIONS}

Bipolar disorder (BPD) describes a pattern of major mood disturbances over an extended period of time that typically crystallizes by early adulthood, although onset may occur at any time [1-3]. The current prototype for this illness is well-characterized for adults, and has four cardinal features: (1) episodes of major depression; interspersed, to greater or lesser degree, with (2) episodes of mania; (3) intervals between episodes whose duration, mood state and quality of functioning vary widely between patients; and (4) an overall course of psychiatric illness that is chronic [4-6].

\section{"Standard” (Classic) Bipolar Disorder Based on Adult Phenomenology}

Bipolar I Disorder is the diagnosis, per DSM-IV, for individuals who have experienced distinct episodes of mania or an episode of major depression with a prior history of mania.

Symptomatically, depression in bipolar disorder does not differ markedly from that seen in individuals without BPD (so-called "unipolar") depression, although it tends to be more persistent and refractory to treatment as our later discussion of pharmacotherapy will elaborate. The classic mood-related abnormality of a manic episode is elation or euphoria, accompanied by an unusually high energy level and the drive and enthusiasm to undertake plans and projects that are often unrealistic and poorly thought out. This frame of mind exerts a severe disinhibitory effect on behavior, which becomes impulsive, erratic, thrill-seeking, and hence

author contact information Joseph C. Blader, Ph.D. Department of Psychiatry School of Medicine Stony Brook State University of New York Stony Brook, NY 11794-8790 USA Tel: (631) 632-8675 Joseph.Blader@ StonyBrook.edu Vivian Kafantaris, M.D. Department of Psychiatry Research The Zucker-Hillside Hospital 75-59263 ${ }^{\text {rd }}$ Street Glen Oaks, NY 11040 USA Tel: (718) 470-8556 VKafanta@lij.edu. 
reckless and irresponsible. Cognitively, appraisals of one's capabilities, assets, or social status become highly exaggerated, which contributes to the brash pursuit of unrealistic aims or inappropriate assertions of entitlement. A significant number of affected individuals, $25 \%$ to $50 \%$ in clinical samples, experience psychotic features [3,7]. These often arise as unshakeable delusions, which aggrandize to impossible extents one's abilities or even one's identity, and as hallucinations that reinforce one's elevated status (e.g., special messages from powerful or famous people or spirits). Paranoid or persecutory delusions focus on dangers associated with having a special mission or being the target of those envious of one's special abilities or status [8]. When the contents of psychotic delusions or hallucinations during a manic episode emphasize one's importance or powers, they are called "mood-congruent". Psychotic symptoms that do not have a clear relationship to inflated worth, such as beliefs in thought insertion or thought broadcasting, or that one really deserves punishment, are considered "mood-incongruent".

Mixed episodes occur when an individual displays the fully syndromal features of both major depression and mania, per DSM-IV criteria, over the course of a single day or other similarly short intervals. Although these sorts of rapid oscillations between deep sadness and intense elation do occur with some frequency, in current usage a "mixed episode" more often refers to the far more prevalent situation in which patients exhibit "blends" of symptoms of depression with those of mania at the same time. In practice, the large majority of individuals diagnosed with a mixed episode are chiefly dysphoric and exhibit an admixture of negative affect and behavioral or cognitive agitation [9-11], rather than the withdrawal and anergy more typical of major depression. For instance, a person may experience a rapid onslaught of vivid thoughts that have morbid or self-loathing content, lash out when upset by minimal or no provocation, or take impulsive actions driven by despondency that have harmful consequences.

The high prevalence of this blending of negative affect with behavioral activation across several varieties of BPD $[9,10]$ has revived a conceptualization of BPD as a "spectrum". The underlying dimensions are (a) overall severity or impairment, and (b) the proportion of manic relative to depressive symptoms. Despite variability in the ratio of manic to depressive symptoms, the thesis is that they are manifestations of a single fundamental illness [12], a view whose origins are attributed to Kraepelin [13].

Besides these manifestations of Bipolar I Disorder, a large group of individuals also experience episodes of major depression and hypomania. Hypomania differs from mania chiefly in terms of severity and level of impairment. That is, one can observe changes in activity level, impulse control, cognition, and mood which are not as egregiously dysfunctional as in mania and which do not involve psychotic features. The diagnosis for an individual with this pattern who had never experienced a full-blown manic episode is Bipolar II disorder. The diagnosis for a person in a hypomanic state with a history of mania would be "Bipolar I Disorder, most recent episode hypomanic."

\section{Bipolar Disorder Among Youth}

The typical period of BPD onset as a syndrome is between 16 and 24 years of age. By the conventional fully-syndromal criteria discussed earlier, the condition becomes less prevalent with decreasing age. Bipolar spectrum disorders affect $0.1 \%$ of children and $1 \%$ of adolescents. Costello and colleagues [14], in an epidemiological study focused on children ages 9-13, and found a lifetime prevalence of hypomania (Bipolar II) of $0.1 \%$. In a community sample of adolescents ages 14 -18 years, Lewinsohn and colleagues [15] estimate a lifetime prevalence of $1 \%$ for bipolar spectrum disorders (primarily bipolar II and cyclothymia). Hypomania is 10 times more prevalent in older adolescents than in children. 
Among adolescents with severe mental illness, BPD represents a large proportion of patients $[16,17]$. Similar to major depression and schizophrenia, early onset tends to bode an overall more pernicious course of illness [18,19]. Depressive episodes tend to precede mania, and at this time there are no features that enable satisfactory prediction of who will have a subsequent manic episode, although the risk increases with family history of BPD. Adolescent onset may be more common among males than females [20], whereas by middle-adulthood hospitalizations for BPD among females outnumber those for males. Full, sustained interepisode recovery from Bipolar I is less common among adolescents, perhaps because the illness itself derails the still-evolving acquisition of cognitive assets and life skills upon which good interepisode functioning depends. Adolescents diagnosed with Bipolar II have a high risk for progression to Bipolar I within two years [18].

"Classic" bipolar disorder with well-delineated episodes is rare among prepubertal children. The diagnosis of BPD among children and adolescents in U.S. clinical settings has proliferated markedly over the last decade $[16,21,22]$. Possible influences on this rise may include a heightened awareness of mood dysregulation in the development of what had hitherto been considered conduct disturbances and the broadening of BPD among adults to a spectrum. Because this spectrum encompasses rather chronic activated dysphoria or irritability, it is consistent with the viewpoint that a similar phenotype among children, characterized by high negative emotional reactivity and deficient impulse control, may constitute a form of juvenile BPD. Children's developmental level and the frequent presence of ADHD, irritability and other difficulties that overlap symptomatically with BPD pose additional challenges in determining whether mood and ideation are really pathognomonic for mania [23,24]. It is common for children to display brief episodes of exaggerated emotionality, such as periodic rageful outbursts or excessive silliness. Problems with emotional dyscontrol and volatile behavior typically develop in the context of longstanding impulsivity and difficult temperament. "Onset" therefore actually better describes the point by late childhood when behavioral upsets either surpass what adults can handle or persist past an age that one can reasonably ascribe such maladaptive behavior to mere developmental delay.

At this time, the continuity between childhood-onset BPD and the "classical" adult form is uncertain, although ongoing studies are expected to furnish data [18,25]. On a provisional basis, Leibenluft and colleagues[26] proposed a subclassification scheme for children in which four categories reflect mainly how far clinical presentation departs from the current adult-oriented DSM-IV criteria. A "narrow phenotype" has a symptom presentation, course, and episodicity fully aligned with current criteria for BPD, with the additional requirement that the mood abnormality be euphoria or there are other signs of pathological grandiosity; irritable mood is excluded. Two "intermediate phenotypes" encompass (a) manic episodes that last from one to three days, instead of the DSM-stipulated seven, and (b) a presentation wherein irritability is the main mood aberration, so long as there is also evidence of well-demarcated episodes. Their final category is a "broad phenotype", denoted as severe behavioral and mood dysregulation, which essentially encapsulates negative emotional reactivity and impulsivity.

In summary, adolescent-onset of BPD is common, and its more pernicious course, in tandem with, as we shall see next, limited data on the efficacy of potential treatments, poses special challenges for management . Among prepubertal children, "classic" BPD is rare, although recent years have witnessed interest in a potential juvenile variant whose core features are deficient impulse control and mood lability, often accompanied by aggressive behavior. Some research cohorts of adolescents may well include both of these clinical pictures. Of course, this heterogeneity in the patient population to whom clinicians and investigators assign the diagnosis of BPD introduces a major caveat toward interpretation of the available literature addressing treatment strategies 


\section{Management of Acute Mania}

\section{Mania without Psychotic Features}

There are surprisingly few controlled studies of pharmacotherapy for mania in adolescents. Part of the difficulty with acquiring such data involves a reluctance to undertake or approve studies that include a placebo condition for acutely ill youngsters, many of whom are admitted to inpatient care. Other relevant data come from open trials and controlled evaluations of adjunctive ("add-on") treatment where all subjects receive at least one active medication. Controlled discontinuation studies (i.e., randomization of responders to continued drug or placebo substitution) may encounter somewhat greater ethical acceptance with adequate safeguards, but the interval to achieve response to open treatment prior to randomization may further blur the already arbitrary boundary between acute and maintenance phases of therapy.

Lithium-One six-week outpatient trial comparing lithium to placebo among 25 adolescents with Bipolar I, II, or major depression with "BPD predictors" and comorbid substance abuse reported advantage for active drug on clinical ratings as well as reduced illicit drug use, measured by urine toxicology [27]. A categorical measure of clinical response classified $46.2 \%$ of the lithium-treated patients as responders, compared with $8 \%$ of those who received placebo.

Hospitalized adolescents who experienced marked improvement of Bipolar I mania during open treatment with lithium were eligible for randomization to double-blind placebo substitution or continuation treatment, in a study whose principal outcome was symptom exacerbation following randomization [17]. Symptom exacerbation was common in both treatment conditions, observed among $52.6 \%$ of lithium-treated subjects and $61.9 \%$ of those randomized to discontinue, and lithium conferred no significant advantage. Among the larger group of patients $(\mathrm{N}=100)$ who began open treatment with lithium as a prelude to possible randomization $63 \%$ exhibited appreciable reductions ( $>=33 \%$ ) in manic symptom ratings and obtained global clinical ratings of at least "much improved" after four weeks [28]. Among these patients, whom investigators classified as responders, $41 \%$ experienced remission of manic symptoms, representing $23 \%$ of the sample. In the absence of a placebo-treated group, the extent to which lithium may have produced or hastened amelioration of manic episodes within a month is uncertain, particularly since the natural course of at least "classic" manic episodes often includes some symptom attenuation within that interval.

Another open trial of lithium involved randomization of 42 8-18 year-old outpatients in a manic or mixed episode of Bipolar I or II disorder to lithium or one of two anticonvulsants, carbamazapine or the valproic acid derivative, divalproex sodium [29]. Using a somewhat more stringent gauge of response, a 50\% reduction on the same manic symptom rating scale used by the previously discussed trial, $38 \%$ of lithium-treated patients achieved this level of improvement, the same rate as with carbamazapine, while divalproex sodium treatment was associated with a 53\% response rate that did not represent a statistically reliable difference between the treatments.

Common difficulties encountered with lithium therapy include increased thirst (polydipsia) and micturition, though water retention and bloating also occur and are a source of discomfort for many adolescent patients. Acne is also a common accompaniment of lithium treatment among adolescents. Estimates for the incidence of lithium-induced tremor vary widely among adults [30]; although adolescent data are lacking, anecdotally tremor can be an impediment to continued lithium treatment or adherence among young people. Lithium inhibits thyroid function, an effect typically overcome by compensatory mechanisms, but for a fair number of patients lithium thyrotoxicity is progressive and requires intervention [31,32]. 
Lithium exhibits very little protein binding, and, being a salt, elimination depends largely on glomerular filtration rate, which varies considerably between people. Therefore, determination of oral dose requires titration against blood concentrations. Blood monitoring and the lab visits it entails can be a sore point among youth, although blood levels do provide an objective index of adherence to treatment. In addition, the relatively narrow range of blood concentrations that are therapeutic, coupled with relatively short elimination half-lives among healthy young people, may render lithium's effectiveness especially vulnerable to inconsistent administration. Adherence to lithium treatment by adolescents can be poor [33,34]

Anti-Epileptic Drugs (AEDs)—Most anticonvulsant drugs seem, in one way or another, to reduce neuronal excitability throughout the brain. Interest in their potential to ameliorate states of high behavioral excitability dates to at least the 1960s when valproic acid and related compounds came into European use as a treatment for bipolar disorder [35,36]. Currently, the most extensively-studied compounds for BPD in adults are divalproex sodium (DVPX) and carbamazapine (CBZ).

Valproate preparations / divalproex spdium: DVPX, an equimolar mixture of valproic acid and sodium valproate, became in 1995 the first anticonvulsant to obtain approval in the U.S. from the Food and Drug Administration (FDA) for the treatment of acute mania. Its off-label use as maintenance therapy also became quite common because a significant proportion of individuals with BPD did not benefit sufficiently from lithium monotherapy [37]. In addition, several reports suggested that DVPX may be more efficacious for patients who experience rapid cycling, which is defined officially[4] as at least four separate episodes within a year but, practically speaking, includes the large group of individuals who are particularly volatile or dysphoric, prone to substance abuse, have poor interepisode functioning and are underresponsive to lithium [38-45]. Some reviews, though, indicate that this advantage for DVPX may be overstated [46].

Despite wide usage of DVPX among youth diagnosed with BPD, however, controlled trials of DVPX for BPD are sparse. A recent placebo-controlled trial involving 15010 to 17 year-old outpatients experiencing a manic or mixed episode of Bipolar I disorder indicated no advantage for DVPX on changes in mania symptom rating scores for DVPX after four weeks of treatment [47]. The specific scores on efficacy measures for the two treatment groups are not yet publicly available.

One open trial involving 407 to 19 year-olds reported a $61 \%$ improvement rate [48], comparable to that noted earlier among adolescents randomized to open treatment with lithium, DVPX, or CBZ [29]. However, only 17 subjects completed the trial and attrition ascribed to intolerance and lack of efficacy was substantial. Although intended as a prelude to a randomized, double-blind discontinuation trial, the number eligible for randomization precluded an adequately powered trial.

DVPX was compared to quetiapine in a study that randomized 50 inpatient adolescents with Bipolar I manic or mixed episodes to receive one of these treatments in a double-blinded fashion [49]. The DVPX group evidenced a 53\% response rate, comparable to the other open studies cited earlier.

As with lithium, DVPX requires titration on the basis of blood concentration, but the "therapeutic window" is somewhat wider relative to lithium (i.e., a broader range of blood levels may prove beneficial and there gradient between therapeutic and toxic levels is not as steep). Hepatic function must be monitored closely, and enzyme elevation is grounds for discontinuation. Many other drugs produce liver enzyme elevations that are transient, and selfregulatory mechanisms often cause hepatocellular injury to cease. However, DVPX and other 
valproate products exert a direct hepatoxic effect in vulnerable patients. Pancreatitis, with potentially fulminating onset, and thrombocytopenia are rare but serious adverse developments with DVPX treatment. DVPX's teratogenicity warrants extra caution with females of childbearing potential. Some reports of adults treated with DVPX suggested increased risk of a hyperandrogenism (polycystic ovaries) syndrome. Evidence to date suggests this effect is mediated chiefly by weight gain and attendant insulin resistance, abetted by possible DVPXinduced hyperinsulinemia [50-52].

Since 2002, DVPX has been available in a once-a-day extended-release preparation that seems to level out peaks and valleys in blood levels seen with other versions which required at least twice-daily administration.

Other antiepileptic drugs: Carbamazepine (CBZ) had been widely used in the treatment of adult BPD, but only recently has an extended-release preparation received U.S. FDA approval for acute mania[53]. Among youth, the randomized open trial mentioned earlier [29] indicated that $38 \%$ of adolescents demonstrated clinical response. No controlled trials have been reported for this age group. CBZ is a strong inhibitor or inducer of several hepatic enzymes important to the metabolism of other psychotropic and other drugs, which complicates its use with other agents, and even in monotherapy CBZ dose may need recalibration because CBZ induces enzymes key to its own metabolism. Heightened risk of neutropenia is also a concern.

Oxcarbazepine (OBZ) is a keto-analog of CBZ, whose catabolism averts the metabolite of CBZ linked to toxicity and is therefore expected to be better tolerated. However, a recent controlled trial for 7 to 18 year-olds with BPD [54] showed no advantage over placebo, and tolerability difficulties led OBZ-treated patients to discontinue treatment at 5 times the rate of those on placebo.

Newer AEDs, topiramate, gabapentin, and lamotrigine have not shown efficacy in the acute treatment of mania in adults, and partly as a result, child and adolescent trials have not gone forward. Lamotrigine, however, has some record of benefit in the maintenance treatment of BPD in adults for which it has an indication.

Antipsychotic Drugs-Historically, antipsychotic medications have held a prominent role as an adjunctive intervention intended to treat the agitation of acutely manic, nonpsychotic adults while lithium titration is underway [55]. In actual clinical practice, though, many such patients continued antipsychotic treatment following episode remission [56]. Whether prolonged antipsychotic treatment conferred any benefit for relapse prophylaxis and interepisode functioning, or resulted from a combination of inertia or wariness to change treatment after stabilization, remains unresolved.

More recently, producers of second-generation antipsychotics have evaluated these newer compounds as monotherapies in the treatment of acute mania in adulthood, as well as its maintenance treatment. The five proprietary compounds in this class (aripiprazole olanzapine, quetiapine, risperidone, ziprasidone) currently have acute mania as an indication approved by the U.S. FDA. A few controlled trials for BPD among children and adolescents are underway or have results pending dissemination.

Another common role for antipsychotic medications in BPD is as cotherapy for the rather large number of patients who experience insufficient response to monotherapy with lithium or an AED, and some data on this use among adolescents suggest their value in this context. The study noted earlier that compared quetiapine with placebo as add-on treatment to DVPX found a significantly higher response rate among those who received active drug (87\% vs. 53\%). Other open trials with youth involving risperidone combined with lithium or DVPX also 
reported response rates upwards of $80 \%$ [57,58,59). However, a Cochrane meta-analysis found no difference between risperidone alone or in combination with mood stabilizers $\{$ Rendell, 2006 \#176].

The liabilities associated with second-generation antipsychotics are by now widely appreciated, and young people are especially susceptible to many of them. In brief, all confer risk of adiposity, though the amount of weight gain differs within the class (in approximate descending order of mean effect size on weight: olanzapine, risperidone, quetiapine, ziprasidone, aripiprazole). Olanzapine's effect on weight seems especially pronounced in young people, and its use in this age group has diminished in recent years. Risperidone is associated with increased prolactin. Ziprasidone can induce cardiac conduction changes, so electrocardiography to monitor QTc interval at baseline and with each dosage adjustment is recommended for youth. The undesirable neuromuscular effects of earlier antipsychotics, which these newer agents had the aim of averting, seem somewhat less but are by no means absent among youth. Collectively still called extrapyramidal symptoms (EPS), an older term that designated disturbances with basal gangliar origins rather than the pyramidal tract proper [60], these effects include hyperkinesias (usually called dyskinesia, and include dystonias, tics, tremors, involuntary large muscle movements, akathisia, etc.) and hypokinesias (Parkinsonlike symptoms). Cessation of a long course of antipsychotic treatment, especially if abrupt, can also precipitate EPS.

\section{Mania with Psychotic Features}

Individuals experiencing psychotic features during a manic episode usually receive antipsychotic treatment acutely, alongside an antimanic agent. This practice may be prudent among young people for whom a history of interepisode recovery, more characteristic of BPD than schizophrenia, has yet to evolve and diagnosis is often unclear especially for the large number who present with a mixed episode. Nonetheless, surprisingly little is known about the value of sustained antipsychotic medication beyond acute stabilization among those with psychotic features.

One study involving 28 hospitalized adolescents with Bipolar I disorder and psychotic feature reported that after stabilization with four weeks of combination therapy (lithium plus haloperidol [54\%], risperidone [21\%], quetiapine [13\%], thiothixene [6\%], or chlorpromazine [6\%]), only $22.9 \%$ did not relapse upon tapering of the antipsychotic agent [61]. Resumption of antipsychotic treatment was associated with improvement. A controlled trial is underway on the role of antipsychotic medication in the maintenance treatment of adolescents with BPD and psychosis.

\section{Special Considerations for Treatment of Children}

The substantial phenotypic differences between most prepubertal children diagnosed with BPD and older individuals with the condition further complicate the always tenuous extrapolation of pharmacotherapy evidence from adults to children. Many of these children also have symptoms and histories characteristic of ADHD, but it is unknown what proportion have been underresponsive to adequate stimulant treatment. Concerns that stimulant treatment may exacerbate mania might have dissuaded clinicians from undertaking stimulant trials with these youngsters, but some data suggest that children with manic symptoms benefit from stimulant treatment [62]. A controlled trial reported that symptoms of ADHD residual to DVPX treatment were highly responsive to the addition of mixed amphetamine salts among youth aged $6-17$ years [63]. 


\section{Management of Depression in Bipolar Disorder}

It is now widely appreciated that most of the time that adults with BPD experience impairment is related to depression rather than mania[64]. However, optimal pharmacotherapy for bipolar depression remains an area of considerable uncertainty and even fewer data are available to guide the treatment of youth.

The main issue concerns the efficacy and safety of adding an antidepressant to an antimanic agent when depressive symptoms break through. The principal worry in doing so concerns the potential for drug-induced "switching", or onset of a manic episode. In adolescents, a metaanalysis of drug approval application data submitted to the FDA found that antidepressants may exacerbate suicidal ideation or behavior among some depressed youth [65]. This finding compounds the issue since bipolar depression itself carries a very high risk for suicide [66]. The second generation antipsychotic medication quetiapine was recently approved by the FDA for treatment of acute bipolar depression in adults [67].

\section{Considerations in Maintenance Treatment and Relapse Prevention}

\section{Course of Illness for Youth with Bipolar Disorder}

Adolescent-onset BPD seems to show, unfortunately, the course of a particularly virulent illness [68], with high rates of serial hospitalizations, substance-abuse, suicides and attempts, less robust response to antimanic medications, and generally worse interepisode functioning than in adult-onset-BPD [19,68-70]. In the short term, an appreciable number of youth seem to recover from the functional nadir of their index episode, but exacerbations and relapse are common [17,18]. In addition, 20-25\% of adolescents diagnosed with bipolar II or bipolar NOS disorders seemed to deteriorate, reflected in their fulfilling criteria for a more severe form of BPD. Risk for adverse outcomes rises with earlier onset, presence of psychotic features, mixed episodes, and low socioeconomic resources [18].

Data from adults have demonstrated the prophylactic value of lithium in reducing risk of relapse into mania and depression, though data for the latter are less consistent [40,71]. Risk of suicide is also appreciably lower among lithium-treated patients in clinical trials compared to those taking placebo or comparator compounds [72], though the influence of patient selection factors (e.g., more severely ill patients enter trials of comparator drugs because they are lithium nonresponders) may affect these findings. Among second-generation antipsychotic medications, all but quetiapine and clozapine have FDA approval for maintenance treatment of BPD as a labeled indication [73]. Lamotrigine is the only agent with no evidence for efficacy in acute treatment that seems beneficial for preventing relapse [74].

Because relapse or symptom exacerbation in young people risks derailing the acquisition of major life skills at a critical time of life, optimizing functioning between episodes takes on exceptional prognostic significance among youth. However, little is known about the relationship between pharmacotherapy and outcomes beyond acute treatment of BPD in youth. In a recent study, 60 children and adolescents with BPD I or II who became euthymic during open, concurrent treatment with lithium and DVPX were randomized to taper and discontinue one of these agents after an average of 11 weeks of cotherapy [75]. The chief outcome was need to discontinue monotherapy due to emerging symptoms suggestive of relapse. Sixty-three percent of those randomized to monotherapy with one drug were reported to experience symptom emergence, mostly manic/hypomanic symptoms. Rates did not differ between those randomized to lithium and DVPX monotherapy. The inclusion of a third arm involving continued cotherapy would have yielded useful information about the sustained benefit of that regimen. Resumption of cotherapy was said to yield improvement [76], but the outcome criteria in these reports differed. 
As among adults, prevention of depressive episodes in adolescents remains a challenge and data are sparse. Extrapolating from adult studies, one anticipates interest in several compounds for this purpose in the coming years. These include the AED lamotrigine, already seen to have benefit as prophylaxis if not acute efficacy [74], and agents with a putatively lower switch rate (bupropion, modafanil [77]). Venlafaxine appears to have an especially high rate of switch induction to hypomania [77].

\section{CURRENT PERSPECTIVES ON PATHOGENESIS AND PATHOPHYSIOLOGY}

\section{Genetics}

No matter how one defines BPD among youth, it seems safe to say that much of the liability for the symptoms in question appears to have a genetic basis. First, in the case of classic (narrow phenotype) BPD, heritability estimates are known to be quite large [78], and early onset BPD may be even more firmly grounded in genetic risk. BPD heritability estimates exceed those for unipolar major depression [79]. Second, if the "broad phenotype" reflects a diathesis of deficient impulse control and affective instability, the heritability for these factors is also exceptionally high [80-84].

Beyond the generalization that susceptibility for BPD has a genetic basis, etiological factors that await clarification include (a) the specific loci of genes that determine vulnerability, (b) their exact impact on cell functions, and (c) the resulting aberrations on specific neurocognitive and neuroaffective systems that eventuate in symptoms. Recent interest has focused on several possibilities, and these are likely to influence research in the near future.

Different genome-scanning studies and meta-analyses have not yielded consistent conclusions about the genetic loci that confer susceptibility for BPD, even when cases are identified using narrow definitions of BPD in adulthood. One analysis reported robust findings implicating chromosomes $13 q$ and $22 q$ [85], while another reported modest effects for an entirely different set of regions on chromosomes 4q, 10q, 14q and 18q [86,87], and in some populations $12 \mathrm{q}$ [88]. Still more recent attention has focused on chromosome $6 \mathrm{q}$, with separate loci related to schizophrenia and to BPD, and perhaps affecting the onset and course of illness [89]. Trying to make sense of this, one recent review of these findings [90], proposed that patterns of symptomatic overlap with other psychiatric disorders may indicate BPD subgroups that share a specific constellation of genetic susceptibilities with these other conditions. That is, preliminary data suggest that genetic liability for BPD with prominent psychotic features may reside in part on chromosomal regions implicated in schizophrenia (13q, 22q), while nonpsychotic high lability and reactivity may be more strongly associated with $12 \mathrm{q}$ and $18 \mathrm{q}$ which have been implicated in vulnerability for anxiety disorders.

Studies of specific genes with known cytochemical functions have also shown some overlap with both schizophrenia and other mood disorders. For instance, the same polymorphisms of the catchol-0-methyltransferase (COMT) gene on chromosome 22q occur with heightened frequency among individuals affected with schizophrenia and BPD. In some studies, brainderived neurotrophic factor (BNDF) polymorphisms have elevated prevalence in samples of those with BPD and unipolar depression [91-93], a finding also replicated in children [94].

\section{Brain Structure and Function}

Reductions in volume of the anterior portions of the cingulate gyrus have been reported in BPD patients and their unaffected close relatives [95]. Among patients themselves, different studies have suggested paucities of white matter, neuronal populations, and dendritic density [96]. Functionally, youth with ADHD also demonstrate underactivity in this region relative to controls during tasks that involve self-monitoring of performance [97]. 
Reduced amygdalar volume has been reported among the first-degree relatives, including children, of adults with BPD $[98,99]$. Among patients themselves, reduced amygdalae volumes have also been reported in BPD [100], but also in other disorders of affective instability [101,102].

A study of 11-18 year-old psychiatric inpatients compared the neurodevelopmental status of youth who had BPD or unipolar depression with psychotic features (per ICD-10) to patients diagnosed with nonpsychotic unipolar depression [103]. The former group had markedly higher rates of premorbid language, motor and social developmental problems, leading the authors to conclude that such difficulties predispose more strongly to BPD than depression. There were no differences in perinatal complications.

Young adults with BPD were more likely to show deficits on the one task often used to measure executive function, the Wisconsin Card Sort Test, when they were tested premorbidly during adolescence, than a group of unipolar depressed young adults who in turn showed no greater impairment than non-ill controls [104].

Learning disabilities have not been studied explicitly to any great extent, but it stands to reason from these findings and the high comorbidity with ADHD that early-onset BPD would carry with it liabilities for academic difficulties. Low scholastic achievement may moderate the course of one's impairment both by impeding the acquisition of key life skills and by imbuing the whole school experience with frustration, stress, and conflict.

\section{Mechanisms of Pharmacotherapeutic Activity}

Two potential mechanisms of action for antimanic drugs are under current consideration, which may bear on how BPD develops.

Inositol is a constituent of phospholipase $\mathrm{C}$, a complex on the interior surface of neuron membranes that breaks down when the synapse-facing G-protein-coupled receptor to which it is attached receives adequate neurotransmitter binding. The breakdown of phospholipase $\mathrm{C}$ is, in effect, the neuron's response to neurotransmission, and sets in motion a number of cellular events. Lithium and other antimanic drugs share the capacity to inhibit free inositol, thereby down-regulating receptor production [105], which leads to the inositol depletion hypothesis for their mechanism. It has been proposed, with some supporting evidence, that inositol-related intracellular cascades may be dysregulated in BPD [106].

It has been known for some time that lithium also inhibits glycogen synthase kinase-3 $\beta$ (GSK3b), an enzyme that regulates some intraneuronal signaling pathways. Recent evidence that valproic acid, an anticonvulsant effective in treating mania, also shares this property [107] has spurred interest in the pathways that involve GSK3-b as perhaps influential in BPD [108].

\section{EXPERT OPINION}

Therapeutic options for the various manifestations and phases of bipolar disorder have proliferated, but solid data on youth remain sparse. In our judgment, lithium remains a very viable treatment whose side effect profile confers some benefits relative to other agents, and has less potential for metabolic interactions with coadministered medications. Its use as either initial therapy or as add-on treatment to address insufficient response warrants strong consideration.

The wide spectrum of symptoms and impairments that an individual with bipolar disorder may experience during the course of this chronic condition has to date necessitated a variety of combination therapies, which have only recently become the subject of empirical trial. The 
relative benefits and liabilities of multiagent treatments in wide clinical use, relative to simpler regimens, is an important topic of investigation.

\section{FIVE-YEAR OUTLOOK}

Development of pharmacotherapy for bipolar disorder to date shows a rather "hand me down" quality. With the exception of lithium, agents first gain regulatory approval and wide usage as anticonvulsant or antipsychotic medications and only later are they screened for their potential viability as therapies for bipolar disorder. Major advances in our understanding of the mechanism of bipolar illness is a reasonable hope over the next five years. That achievement may in turn set the stage for rational drug development programs based on specific molecular targets and processes.

In addition, further work on elucidating the mechanisms involved in affective regulation and impulse control is crucial. In particular, it is unclear whether the emotional and behavioral volatility characteristic of childhood bipolar disorder stems from the same perturbations that lead to later-onset illness. The former may involve abnormalities in developmental processes to produce a chronic condition with some phenotypic overlap with the latter, although "classic", later-evolving bipolar disorder may have a quite different genesis.

This time frame will also witness the completion of a second large placebo-controlled trial of lithium in children and adolescents with Bipolar I disorder.

Polytherapy is likely to reign for the foreseeable future given the apparent complexity of the multiple manifestation of the disorder (mania, depression, psychosis, etc.), and the concomitant difficulties that poses for any single agent to manage them all effectively over time.

The capacity to predict an individual's response to a particular agent has major implications both for the commercialization of therapeutic products and for hastening remission in patients. Activity in this area may in the next five years yield some genetic markers of likely responsiveness, as well as vulnerability to side effects. These markers may include both polymorphisms putatively related to the illness itself or to metabolism of the individual compound.

\section{KEY ISSUES}

- Bipolar disorder has a range of clinical presentations and impairments to which patients are vulnerable over time.

- Among its other perils, adolescence is a frequent time of life for the onset of major mood disorders. Differential diagnosis remains tricky but important, to enable both timely intervention and avoidance of drug-induced switching.

- Preadolescent bipolar disorder is increasingly diagnosed. The continuity of various phenotypes with more "classical" presentations awaits clarification.

- The pathophysiology of bipolar disorder in general remains poorly understood. Moreover, one cannot take for granted that the same mechanisms that influence later-onset illness will apply to childhood-onset condition, where symptoms are typically evident very early in life. The implication for pharmacotherapy and drug development is caution about regarding the developing child brain as just a smaller version of the adult brain. 
- Depression in bipolar disorder has recently become a major focus of clinical trials, and some promising treatments identified. Their benefits for younger patients requires further study.

\section{Acknowledgments}

This work was supported in part by funding from NIMH grant K23MH064975 (to JCB) and from a National Alliance for Research on Schizophrenia and Depression (NARSAD) Young Investigator Award (to JCB).

JCB receives research support from Abbott Laboratories, NARSAD, and NIMH. VK received research support from AstraZeneca, GlaxoSmithKline, Janssen L.P., Eli Lilly \& Co., NIMH, and Pfizer Inc..

\section{REFERENCES}

1. Schaffer A, Cairney J, Cheung A, Veldhuizen S, Levitt A. Community survey of bipolar disorder in Canada: lifetime prevalence and illness characteristics. Can. J. Psychiatry 2006;51(1):9-16. [PubMed: 16491979]

2. Weissman MM, Bland RC, Canino GJ, et al. Cross-national epidemiology of major depression and bipolar disorder. JAMA 1996;276(4):293-299. [PubMed: 8656541]

3. Kennedy N, Boydell J, Kalidindi S, et al. Gender differences in incidence and age at onset of mania and bipolar disorder over a 35-year period in Camberwell, England. Am. J. Psychiatry 2005;162(2): 257-262. [PubMed: 15677588]

4. American Psychiatric Association. Diagnostic and Statistical Manual of Mental Disorders. 4th Edition. American Psychiatric Press; Washington, DC, USA: 2000. text revision

5. Goodwin, FK.; Jamison, KR., editors. Manic-Depressive llness: Bipolar and Recurrent Depression. 2nd Edition. Oxford University Press; New York, USA: 2007.

6. World Health Organization. The International Statistical Classification of Diseases and Related Health Problems. WHO Press; Geneva, Switzerland: 2004. Chapter V, Mental and behavioural disorders..

7. Müller-Oerlinghausen B, Berghöfer A, Bauer M. Bipolar disorder. Lancet 2002;359(9302):241-247. [PubMed: 11812578]

8. Keck PE Jr. McElroy SL, Havens JR, et al. Psychosis in bipolar disorder: Phenomenology and impact on morbidity and course of illness. Compr. Psychiatry 2003;44(4):263-269. [PubMed: 12923703]

9. Maj M, Pirozzi R, Magliano L, Bartoli L. Agitated depression in bipolar I disorder: Prevalence, phenomenology, and outcome. Am. J. Psychiatry 2003;160(12):2134-2140. [PubMed: 14638583]

10. Bauer MS, Simon GE, Ludman E, Unützer J. 'Bipolarity' in bipolar disorder: Distribution of manic and depressive symptoms in a treated population. Br. J. Psychiatry 2005;187(1):87-88. [PubMed: 15994577]

11. Akiskal HS. The prevalent clinical spectrum of bipolar disorders: Beyond DSM-IV. J. Clin. Psychopharmacol 1996;16(2 Suppl. 1):4S-14S. [PubMed: 8707999]

12. Benazzi F, Akiskal H. Irritable-hostile depression: Further validation as a bipolar depressive mixed state. J. Affect. Disord 2005;84(2-3):197-207. [PubMed: 15708417]

13. Kraepelin, E. Manic-Depressive Insanity and Paranoia.. In: Robertson, GM.; Barclay, RM.; E.; Livingstone, S.; Edinburgh, UK., editors. Reprinted 1976 by Ayer Publishing; Salem, NH, USA: 1921.

14. Costello EJ, Angold A, Burns BJ, et al. The Great Smoky Mountains Study of Youth. Goals, design, methods, and the prevalence of DSM-III-R disorders. Arch. Gen. Psychiatry 1996;53(12):1129_ 1136. [PubMed: 8956679]

15. Lewinsohn PM, Klein DN, Seeley JR. Bipolar disorders in a community sample of older adolescents: Prevalence, phenomenology, comorbidity, and course. J. Am. Acad. Child Adolesc. Psychiatry 1995;34(4):454-463. [PubMed: 7751259]

16. Blader JC, Carlson GA. Increased rates of bipolar disorder diagnoses among U.S. child, adolescent, and adolescent inpatients, 1996-2004. Biol. Psychiatry. in press. 
17. Kafantaris V, Coletti DJ, Dicker R, Padula G, Pleak RR, Alvir JMJ. Lithium treatment of acute mania in adolescents: A placebo-controlled discontinuation study. J. Am. Acad. Child Adolesc. Psychiatry 2004;43(8):984-993. [PubMed: 15266193]

18. Birmaher B, Axelson D, Strober M, et al. Clinical course of children and adolescents with bipolar spectrum disorders. Arch. Gen. Psychiatry 2006;63(2):175-183. [PubMed: 16461861]

19. Goldstein TR, Birmaher B, Axelson D, et al. History of suicide attempts in pediatric bipolar disorder: Factors associated with increased risk. Bipolar Disord 2005;7(6):525-535. [PubMed: 16403178]

20. Kennedy N, Everitt B, Boydell J, van Os J, Jones PB, Murray RM. Incidence and distribution of firstepisode mania by age: Results from a 35-year study. Psychol. Med 2005;35(6):855-863. [PubMed: 15997605]

21. Soutullo CA, Chang KD, Díez-Suárez A, et al. Bipolar disorder in children and adolescents: International perspective on epidemiology and phenomenology. Bipolar Disord 2005;7(6):497-506. [PubMed: 16403175]

22. Harpaz-Rotem I, Leslie DL, Martin A, Rosenheck RA. Changes in child and adolescent inpatient psychiatric admission diagnoses between 1995 and 2000. Soc. Psychiatry Psychiatr. Epidemiol 2005;40(8):642-647. [PubMed: 16133747]

23. Carlson GA, Meyer SE. Phenomenology and diagnosis of bipolar disorder in children, adolescents, and adults: Complexities and developmental issues. Dev. Psychopathol 2006;18(6):939-969. [PubMed: 17064424]

24. Brotman MA, Schmajuk M, Rich BA, et al. Prevalence, clinical correlates, and longitudinal course of severe mood dysregulation in children. Biol. Psychiatry 2006;60(9):991-997. [PubMed: 17056393]

25. Geller B, Tillman R, Craney JL, Bolhofner K. Four-year prospective outcome and natural history of mania in children with a prepubertal and early adolescent bipolar disorder phenotype. Arch. Gen. Psychiatry 2004;61(5):459-467. [PubMed: 15123490]

26. Leibenluft E, Charney DS, Towbin KE, Bhangoo RK, Pine DS. Defining clinical phenotypes of juvenile mania. Am. J. Psychiatry 2003;160(3):430-437. [PubMed: 12611821]

27. Geller B, Cooper TB, Sun K, et al. Double-blind and placebo-controlled study of lithium for adolescent bipolar disorders with secondary substance dependency. J. Am. Acad. Child Adolesc. Psychiatry 1998;37(2):171-178. [PubMed: 9473913]

28. Kafantaris V, Coletti DJ, Dicker R, Padula G, Kane JM. Lithium treatment of acute mania in adolescents: A large open trial. J. Am. Acad. Child Adolesc. Psychiatry 2003;42(9):1038-1045. [PubMed: 12960703]

29. Kowatch RA, Suppes T, Carmody TJ, et al. Effect size of lithium, divalproex sodium, and carbamazepine in children and adolescents with bipolar disorder. J. Am. Acad. Child Adolesc. Psychiatry 2000;39(6):713-720. [PubMed: 10846305]

30. Gelenberg AJ, Jefferson JW. Lithium tremor. J. Clin. Psychiatry 1995;56(7):283-287. [PubMed: 7615481]

31. Bocchetta A, Loviselli A. Lithium treatment and thyroid abnormalities. Clinical Practice and Epidemiology in Mental Health 2006;2 Article 23 [doi: 10.1186/1745-0179-2-23].

32. Fagiolini A, Kupfer DJ, Scott J, et al. Hypothyroidism in patients with bipolar I disorder treated primarily with lithium. Epidemiologia e Psichiatria Sociale 2006;15(2):123-127. [PubMed: 16865933]

33. Strober M, Morrell W, Lampert C, Burroughs J. Relapse following discontinuation of lithium maintenance therapy in adolescents with bipolar I illness: a naturalistic study. Am. J. Psychiatry 1990;147(4):457-461. [PubMed: 2107763]

34. Strober M, Schmidt-Lackner S, Freeman R, Bower S, Lampert C, DeAntonio M. Recovery and relapse in adolescents with bipolar affective illness: A five-year naturalistic, prospective follow-up. J. Am. Acad. Child Adolesc. Psychiatry 1995;34(6):724-731. [PubMed: 7608045]

35. Macritchie KA, Geddes JR, Scott J, Haslam DR, Goodwin GM. Valproic acid, valproate and divalproex in the maintenance treatment of bipolar disorder. Cochrane Database Syst. Rev. 2001;(3) Article no. CD003196.

36. Lempérière T. Historique du développement du valproate dans les troubles bipolaires [Brief history of the development of valproate in bipolar disorders]. L'Encéphale 2001;27(4):365-372. 
37. Muzina DJ, Calabrese JR. Maintenance therapies in bipolar disorder: Focus on randomized controlled trials. Aust. N. Z. J. Psychiatry 2005;39(8):652-661. [PubMed: 16050919]

38. Kupka RW, Luckenbaugh DA, Post RM, et al. Comparison of rapid-cycling and non-rapid-cycling bipolar disorder based on prospective mood ratings in 539 outpatients. Am. J. Psychiatry 2005;162 (7):1273-1280. [PubMed: 15994709]

39. Mackinnon DF, Pies R. Affective instability as rapid cycling: Theoretical and clinical implications for borderline personality and bipolar spectrum disorders. Bipolar Disord 2006;8(1):1-14. [PubMed: 16411976]

40. Bowden CL, Lecrubier Y, Bauer M, et al. Maintenance therapies for classic and other forms of bipolar disorder. J. Affect. Disord 2000;59(Suppl 1):S57-S67. [PubMed: 11121827]

41. Kramlinger K, Post R. Ultra-rapid and ultradian cycling in bipolar affective illness. Br. J. Psychiatry 1996;168(3):314-323. [PubMed: 8833685]

42. Suppes T, Brown E, Schuh LM, Baker RW, Tohen M. Rapid versus non-rapid cycling as a predictor of response to olanzapine and divalproex sodium for bipolar mania and maintenance of remission: Post hoc analyses of 47-week data. J. Affect. Disord 2005;89(1-3):69-77. [PubMed: 16253344]

43. Grunze H, Walden J. Relevance of new and newly rediscovered anticonvulsants for atypical forms of bipolar disorder. J. Affect. Disord 2002;72(Suppl. 1):S15-S21. [PubMed: 12589899]

44. Bowden CL. Clinical correlates of therapeutic response in bipolar disorder. J. Affect. Disord 2001;67 (1-3):257-265. [PubMed: 11869775]

45. Coryell W. Rapid cycling bipolar disorder: Clinical characteristics and treatment options. CNS Drugs 2005;19(7):557-569. [PubMed: 15984894]

46. Tondo L, Hennen J, Baldessarini RJ. Rapid-cycling bipolar disorder: effects of long-term treatments. Acta. Psychiatr. Scand 2003;108(1):4-14. [PubMed: 12807371]

47. Abbott Laboratories. Clinical Study Report: A Double-Blind, Placebo-Controlled Trial to Evaluate the Safety and Efficacy of Depakote ER for the Treatment of Mania Associated with Bipolar Disorder in Children and Adolescents (Document no. ABT-711, M01-342, R\&D/06/054). Abbott Park, IL, USA (2006). Online at http://www.clinicalstudyresults.org/documents/companystudy_1561_0.pdf.

48. Wagner KD, Weller EB, Carlson GA, et al. An open-label trial of divalproex in children and adolescents with bipolar disorder. J. Am. Acad. Child Adolesc. Psychiatry 2002;41(10):1224-1230. [PubMed: 12364844]

49. DelBello MP, Kowatch RA, Adler CM, et al. A double-blind randomized pilot study comparing quetiapine and divalproex for adolescent mania. J. Am. Acad. Child Adolesc. Psychiatry 2006;45 (3):305-313. [PubMed: 16540815]

50. Luef G, Abraham I, Haslinger M, et al. Polycystic ovaries, obesity and insulin resistance in women with epilepsy. A comparative study of carbamazepine and valproic acid in 105 women. Journal of Neurology 2002;249(7):835-841. [PubMed: 12140666]

51. McIntyre R, Mancini D, McCann S, Srinivasan J, Kennedy S. Valproate, bipolar disorder and polycystic ovarian syndrome. Bipolar Disord 2003;5(1):28-35. [PubMed: 12656935]

52. Joffe H, Cohen LS, Suppes T, et al. Valproate is associated with new-onset oligoamenorrhea with hyperandrogenism in women with bipolar disorder. Biol. Psychiatry 2006;59(11):1078-1086. [PubMed: 16448626]

53. Goldberg JF, Citrome L. Latest therapies for bipolar disorder: Looking beyond lithium. Postgraduate Medicine 2005;117(2):25-36. [PubMed: 15745123]

54. Wagner KD, Kowatch RA, Emslie GJ, et al. A double-blind, randomized, placebo-controlled trial of oxcarbazepine in the treatment of bipolar disorder in children and adolescents. Am. J. Psychiatry 2006;163(7):1179-1186. [PubMed: 16816222]

55. Kane JM. The role of neuroleptics in manic-depressive illness. J. Clin. Psychiatry 1988;49(Suppl. 11):12-14. [PubMed: 2903142]

56. Sernyak MJ, Griffin RA, Johnson RM, Pearsall HR, Wexler BE, Woods SW. Neuroleptic exposure following inpatient treatment of acute mania with lithium and neuroleptic. Am. J. Psychiatry 1994;151(1):133-135. [PubMed: 7903511] 
57. Biederman J, Mick E, Wozniak J, Aleardi M, Spencer T, Faraone SV. An open-label trial of risperidone in children and adolescents with bipolar disorder. J. Child Adolesc. Psychopharmacol 2005;15(2):311-317. [PubMed: 15910215]

58. Pavuluri MN, Henry DB, Carbray JA, Sampson G, Naylor MW, Janicak PG. Open-label prospective trial of risperidone in combination with lithium or divalproex sodium in pediatric mania. J. Affect. Disord 2004;82(Suppl. 1):103-111.

59. Rendell JM, Gijsman HJ, Bauer MS, Goodwin GM, Geddes GR. Risperidone alone or in combination for acute mania. Cochrane Database Syst. Rev 2006;(1):CD004043. [PubMed: 16437472]

60. Fahn, S. Hypokinesia and hyperkinesia.. In: Goetz, CG., editor. Textbook of Clinical Neurology. 2nd Edition. W.B. Saunders; Philadelphia, USA: 2003. p. **_**.

61. Kafantaris V, Coletti DJ, Dicker R, Padula G, Kane JM. Adjunctive antipsychotic treatment of adolescents with bipolar psychosis. J. Am. Acad. Child Adolesc. Psychiatry 2001;40(12):1448-1456. [PubMed: 11765291]

62. Carlson GA, Loney J, Salisbury H, Kramer JR, Arthur C. Stimulant treatment in young boys with symptoms suggesting childhood mania: A report from a longitudinal study. J. Child Adolesc. Psychopharmacol 2000;10(3):175-184. [PubMed: 11052407]

63. Scheffer RE, Kowatch RA, Carmody T, Rush AJ. Randomized, placebo-controlled trial of mixed amphetamine salts for symptoms of comorbid ADHD in pediatric bipolar disorder after mood stabilization with divalproex sodium. Am. J. Psychiatry 2005;162(1):58-64. [PubMed: 15625202]

64. Judd LL, Akiskal HS, Schettler PJ, et al. The long-term natural history of the weekly symptomatic status of Bipolar I disorder. Arch. Gen. Psychiatry 2002;59(6):530-537. [PubMed: 12044195]

65. Hammad TA, Laughren T, Racoosin J. Suicidality in pediatric patients treated with antidepressant drugs. Arch. Gen. Psychiatry 2006;63(3):332-339. [PubMed: 16520440]

66. Suppes T, Kelly DI, Perla JM. Challenges in the management of bipolar depression. J. Clin. Psychiatry 2005;66(Suppl. 5):11-16. [PubMed: 16038597]

67. Thase ME, Macfadden W, Weisler RH, et al. Efficacy of quetiapine monotherapy in bipolar I and II depression: A double-blind, placebo-controlled study (the BOLDER II Study). J. Clin. Psychopharmacol 2006;26(6):600-609. [PubMed: 17110817]

68. Lewinsohn PM, Seeley JR, Klein DN. Bipolar disorders during adolescence. Acta. Psychiatr. Scand 2003;108(Suppl. 418):47-50.

69. Wilcox HC, Anthony JC. Child and adolescent clinical features as forerunners of adult-onset major depressive disorder: Retrospective evidence from an epidemiological sample. J. Affect. Disord 2004;82(1):9-20. [PubMed: 15465572]

70. Axelson D, Birmaher B, Strober M, et al. Phenomenology of children and adolescents with bipolar spectrum disorders. Arch. Gen. Psychiatry 2006;63(10):1139-1148. [PubMed: 17015816]

71. Bowden CL. Acute and maintenance treatment with mood stabilizers. Int. J. Neuropsychopharmacol 2003;6(3):269-275. [PubMed: 12974993]

72. Cipriani A, Pretty H, Hawton K, Geddes JR. Lithium in the prevention of suicidal behavior and allcause mortality in patients with mood disorders: A systematic review of randomized trials. Am. J. Psychiatry 2005;162(10):1805-1819. [PubMed: 16199826]

73. Gajwani P, Kemp DE, Muzina DJ, Xia G, Gao K, Calabrese JR. Acute treatment of mania: An update on new medications. Curr. Psychiatry Rep 2006;8(6):504-509. [PubMed: 17094930]

74. Bowden CL, Calabrese JR, Sachs G, et al. A placebo-controlled 18-month trial of lamotrigine and lithium maintenance treatment in recently manic or hypomanic patients with bipolar I disorder. Arch. Gen. Psychiatry 2003;60(4):392-400. [PubMed: 12695317]

75. Findling RL, McNamara NK, Youngstrom EA, et al. Double-blind 18-month trial of lithium versus divalproex maintenance treatment in pediatric bipolar disorder. J. Am. Acad. Child Adolesc. Psychiatry 2005;44(5):409-417. [PubMed: 15843762]

76. Findling R, Youngstrom E, McNamara N, et al. Restabilization of mood symptoms with lithium and divalproex sodium in children and adolescents with bipolar disorder [poster abstract]. Bipolar Disord 2005;7(Suppl 2):53. [PubMed: 16225561]

77. Leverich GS, Altshuler LL, Frye MA, et al. Risk of switch in mood polarity to hypomania or mania in patients with bipolar depression during acute and continuation trials of venlafaxine, sertraline, and 
bupropion as adjuncts to mood stabilizers. Am. J. Psychiatry 2006;163(2):232-239. [PubMed: 16449476]

78. McGuffin P, Rijsdijk F, Andrew M, Sham P, Katz R, Cardno A. The heritability of bipolar affective disorder and the genetic relationship to unipolar depression. Arch. Gen. Psychiatry 2003;60(5):497502. [PubMed: 12742871]

79. Craddock N, Forty L. Genetics of affective (mood) disorders. Eur. J. Hum. Genet 2006;14(6):660668. [PubMed: 16721402]

80. Rietveld MJH, Hudziak JJ, Bartels M, van Beijsterveldt CEM, Boomsma DI. Heritability of attention problems in children: Longitudinal results from a study of twins, age 3 to 12. J. Child Psychol. Psychiatry 2004;45(3):577-588. [PubMed: 15055376]

81. Rujescu D, Giegling I, Bondy B, Gietl A, Zill P, Möller H-J. Association of anger-related traits with SNPs in the TPH gene. Mol. Psychiatry 2002;7(9):1023-1029. [PubMed: 12399958]

82. Todd RD, Rasmussen ER, Neuman RJ, et al. Familiality and heritability of subtypes of attention deficit hyperactivity disorder in a population sample of adolescent female twins. Am. J. Psychiatry 2001;158(11):1891-1898. [PubMed: 11691697]

83. Coccaro EF, Bergeman CS, Kavoussi RJ, Seroczynski AD. Heritability of aggression and irritability: A twin study of the Buss-Durkee aggression scales in adult male subjects. Biol. Psychiatry 1997;41 (3):273-284. [PubMed: 9024950]

84. Cates DS, Houston BK, Vavak CR, Crawford MH, Uttley M. Heritability of hostility-related emotions, attitudes, and behaviors. J. Behav. Med 1993;16(3):237-256. [PubMed: 8350340]

85. Badner JA, Gershon ES. Meta-analysis of whole-genome linkage scans of bipolar disorder and schizophrenia. Mol. Psychiatry 2002;7(4):405-411. [PubMed: 11986984]

86. Segurado R, Detera-Wadleigh SD, Levinson DF, et al. Genome scan meta-analysis of schizophrenia and bipolar disorder, part III: Bipolar disorder. Am. J. Hum. Genet 2003;73(1):49-62. [PubMed: 12802785]

87. Lambert D, Middle F, Hamshere ML, et al. Stage 2 of the Wellcome Trust UK-Irish bipolar affective disorder sibling-pair genome screen: Evidence for linkage on chromosomes 6q16-q21, 4q12-q21, 9p21, 10p14-p12 and 18q22. Mol. Psychiatry 2005;10(9):831-841. [PubMed: 15940300]

88. Curtis D, Kalsi G, Brynjolfsson J, et al. Genome scan of pedigrees multiply affected with bipolar disorder provides further support for the presence of a susceptibility locus on chromosome 12q23q24, and suggests the presence of additional loci on 1p and 1q. Psychiatr. Genet 2003;13(2):77-84. [PubMed: 12782963]

89. Kohn Y, Lerer B. Excitement and confusion on chromosome 6q: The challenges of neuropsychiatric genetics in microcosm. Mol. Psychiatry 2005;10(12):1062-1073. [PubMed: 16172614]

90. MacQueen GM, Hajek T, Alda M. The phenotypes of bipolar disorder: Relevance for genetic investigations. Mol. Psychiatry 2005;10(9):811-826. [PubMed: 15970930]

91. Levinson DF. The genetics of depression: A review. Biol. Psychiatry 2006;60(2):84-92. [PubMed: 16300747]

92. Okada T, Hashimoto R, Numakawa T, et al. A complex polymorphic region in the brain-derived neurotrophic factor (BDNF) gene confers susceptibility to bipolar disorder and affects transcriptional activity. Mol. Psychiatry 2006;11(7):695-703. [PubMed: 16568151]

93. Kremeyer B, Herzberg I, Garcia J, et al. Transmission distortion of BDNF variants to bipolar disorder type I patients from a South American population isolate. Am. J. Med. Genet. B. Neuropsychiatr. Genet 2006;141(5):435-439. [PubMed: 16741941]

94. Strauss J, Barr CL, George CJ, et al. Brain-derived neurotrophic factor variants are associated with childhood-onset mood disorder: Confirmation in a Hungarian sample. Mol. Psychiatry 2005;10(9): 861-867. [PubMed: 15940299]

95. McDonald C, Bullmore ET, Sham PC, et al. Association of genetic risks for schizophrenia and bipolar disorder with specific and generic brain structural endophenotypes. Arch. Gen. Psychiatry 2004;61 (10):974-984. [PubMed: 15466670]

96. Harrison PJ. The neuropathology of primary mood disorder. Brain 2002;125(7):1428-1449. [PubMed: 12076995] 
97. Pliszka SR, Glahn DC, Semrud-Clikeman M, et al. Neuroimaging of inhibitory control areas in children with attention deficit hyperactivity disorder who were treatment naïve or in long-term treatment. Am. J. Psychiatry 2006;163(6):1052-1060. [PubMed: 16741206]

98. Chang K, Karchemskiy A, Barnea-Goraly N, Garrett A, Simeonova DI, Reiss A. Reduced amygdalar gray matter volume in familial pediatric bipolar disorder. J. Am. Acad. Child Adolesc. Psychiatry 2005;44(6):565-573. [PubMed: 15908839]

99. Hajek T, Carrey N, Alda M. Neuroanatomical abnormalities as risk factors for bipolar disorder. Bipolar Disord 2005;7(5):393-403. [PubMed: 16176432]

100. Blumberg HP, Fredericks C, Wang F, et al. Preliminary evidence for persistent abnormalities in amygdala volumes in adolescents and young adults with bipolar disorder. Bipolar Disord 2005;7 (6):570-576. [PubMed: 16403182]

101. Rosso IM, Cintron CM, Steingard RJ, Renshaw PF, Young AD, Yurgelun-Todd DA. Amygdala and hippocampus volumes in pediatric major depression. Biol. Psychiatry 2005;57(1):21-26. [PubMed: 15607296]

102. Szeszko PR, Robinson D, Alvir JMJ, et al. Orbital frontal and amygdala volume reductions in obsessive-compulsive disorder. Arch. Gen. Psychiatry 1999;56(10):913-919. [PubMed: 10530633]

103. Sigurdsson E, Fombonne E, Sayal K, Checkley S. Neurodevelopmental antecedents of early-onset bipolar affective disorder. Br. J. Psychiatry 1999;174(1):121-127. [PubMed: 10211165]

104. Meyer SE, Carlson GA, Wiggs EA, et al. A prospective study of the association among impaired executive functioning, childhood attentional problems, and the development of bipolar disorder. Dev. Psychopathol 2004;16(2):461-476. [PubMed: 15487606]

105. Williams RS, Cheng L, Mudge AW, Harwood AJ. A common mechanism of action for three moodstabilizing drugs. Nature 2002;417(6886):292-295. [PubMed: 12015604]

106. Silverstone PH, Wu RH, O'Donnell T, Ulrich M, Asghar SJ, Hanstock CC. Chronic treatment with both lithium and sodium valproate may normalize phosphoinositol cycle activity in bipolar patients. Hum. Psychopharmacol 2002;17(7):321-327. [PubMed: 12415549]

107. Eickholt BJ, Towers GJ, Ryves WJ, et al. Effects of valproic acid derivatives on inositol trisphosphate depletion, teratogenicity, glycogen synthase kinase- $3 \beta$ inhibition, and viral replication: A screening approach for new bipolar disorder drugs derived from the valproic acid core structure. Mol. Pharmacol 2005;67(5):1426-1433. [PubMed: 15687223]

108. Einat H, Manji HK. Cellular plasticity cascades: Genes-to-behavior pathways in animal models of bipolar disorder. Biol. Psychiatry 2006;59(12):1160-1171. [PubMed: 16457783] 